\title{
What is the link between endometriosis and adiposity?
}

\author{
Juyeon Hong, MD, Kyong Wook Yi, MD, PhD \\ Department of Obstetrics and Gynecology, Korea University Ansan Hospital, Korea University College of Medicine, Ansan, Korea
}

Endometriosis is defined by the presence of extrauterine endometrial tissue and presents with symptoms of dysmenorrhea, chronic pelvic pain, and impaired fertility. This condition often follows a chronic progressive course with favorable recurrence, even after surgical or medical treatment. The etiology or exact pathophysiology of endometriosis remains to be clarified, although it is thought to be a complex and multifactorial disease. Prior epidemiological or population-based studies have reported several risk factors related to endometriosis, such as environmental, menstrual, habitual, and lifestyle factors. Moreover, anthropometry has been found to be significantly associated with the diagnosis of endometriosis, as a lower body mass index is associated with an elevated risk of endometriosis. Here, we review studies that have examined the association between body size and the risk of endometriosis and discuss the clinical and biological significance of the relationship between adiposity and endometriosis.

Keywords: Endometriosis; Adiposity; Anthropometry; Obesity; Adipokines

\section{Introduction}

Endometriosis is defined as the ectopic implantation of endometrial cells outside the uterus [1]. The prevalence of endometriosis is estimated to be approximately $10 \%$ in reproductive-aged women, and $30-50 \%$ in symptomatic women [2-5]. Endometriosis often presents with symptoms, such as dysmenorrhea, pelvic pain, and infertility, which may result in profuse morbidity in chronic conditions and reduced quality of life.

The natural history and exact pathogenesis of endometriosis are not fully understood, but the most cited theory is that endometrial cells in retrograde menstruation into the pelvic cavity are implanted and grown by the complex effects of immune, angiogenic, and growth factors $[6,7]$. Other pathogenic theories, such as lymphatic, hematogenous, and mechanical spread of endometrial fragments, have been suggested for extrapelvic endometriosis $[8,9]$.

Worldwide epidemiological studies have focused on the risk factors for endometriosis and identified that race, ethnicity, lifestyle, and habitual factors such as diet, exercise, caffeine consumption, and smoking are associated with endometriosis diagnosis. However, some of these associations have shown conflicting results [10-13]. Menstrual and reproductive risk factors have less controversial associations with endometriosis. Moreover, lower parity, earlier age at menarche, shorter menstrual cycle, heavier menstrual volume, and longtime tampon use increase the risk of endometriosis [13-15].

Many studies have addressed the significant association between anthropometric parameters and the incidence of endometriosis. Here, we review the studies that have examined the association between the risk of endometriosis and body size as well as discuss the clinical and biological relevance of the findings and proposed mechanisms involved in adiposity and endometriosis.

Received: 2021.11.13. Accepted: 2021.12.08.

Corresponding author: Kyong Wook Yi, MD, PhD

Department of Obstetrics and Gynecology, Korea University Ansan Hospital, Korea University College of Medicine, 123 Jeokgeum-ro, Danwon-gu, Ansan 15355, Korea

E-mail: kwyi@korea.ac.kr

https://orcid.org/0000-0001-7059-640X

Kyong Wook Yi has been an Editorial Board of Obstetrics \& Gynecology Science; however, he was not involved in the peer reviewer selection, evaluation, or decision process of this article. Otherwise, no other potential conflicts of interest relevant to this article were reported.

Articles published in Obstet Gynecol Sci are open-access, distributed under the terms of the Creative Commons Attribution Non-Commercial License (http://creativecommons. org/licenses/by-nc/3.0/) which permits unrestricted non-commercial use, distribution, and reproduction in any medium, provided the original work is properly cited.

Copyright $\odot 2022$ Korean Society of Obstetrics and Gynecology 


\section{Obstetrics \& Gynecology Science}

Vol. 65, No. 3, 2022

\section{Body size and the risk of endometriosis in population-based studies}

\section{Body mass index (BMI) is associated with the diagnosis of endometriosis}

Many epidemiological and population studies on risk factors for endometriosis have used anthropometric indices to estimate body size; these studies have shown that endometriosis is associated with lower BMI and less obesity, suggesting an inverse relationship between $\mathrm{BMI}$ and the risk of endometriosis [11,13,16-19]. A hospital-based case-control study with 50 women with endometriosis and 89 controls found that the risk of endometriosis was positively associated with height (odds ratio [OR], 2.8 per $10 \mathrm{~cm}$ increase; 95\% confidence interval [CI], 1.4-5.6) and inversely associated with weight $(\mathrm{OR}, 0.7$ per $10 \mathrm{~kg}$ increase; $95 \% \mathrm{Cl}, 0.5$ 1.0) and $\mathrm{BMI}\left(\mathrm{OR}, 0.7\right.$ per $5 \mathrm{~kg} / \mathrm{m}^{2}$ increase; $\left.95 \% \mathrm{Cl}, 0.4-1.1\right)$ [16]. Another case-control study analyzed the relationship between diet and risk of endometriosis and found an inverse relationship between $\mathrm{BMI}$ and the risk of endometriosis [19]. Similarly, a study of 366 Italian women laparoscopically diagnosed with endometriosis and 248 controls showed that women with endometriosis had a lower BMI than controls and were less frequently obese and more frequently thin [17]. Consistent findings have been observed in two case-control studies of Iranian women $[20,21]$.

A recent meta-analysis including a quantitative investigation of 11 studies (two cohort and nine case-control studies) reported that a higher BMI correlates with a lower risk of endometriosis. The overall analysis showed a 33\% reduction in the risk of endometriosis for each $5 \mathrm{~kg} / \mathrm{m}^{2}$ increase in BMI [22]. Compared with those with normal weight, the pooled relative risk for obese women was $0.89(95 \% \mathrm{Cl}$, 0.83-0.96). They suggest that several issues need to be considered in their findings, as BMI is a widely utilized indirect marker for estimating body size and obesity, but it may not provide enough etiological information to reflect the nature of obesity. In addition, the inverse relationship between obesity and endometriosis may be attributed to diagnostic bias, where obese women with pelvic pain may be less likely to be provided with an operative intervention, which may subsequently lower the possibility of a laparoscopic diagnosis of endometriosis [22].

Several studies have explored the historical relationship between obesity and endometriosis by analyzing the personal characteristics of body size in adolescence or early adult life, thereby underscoring obesity as a preceding factor involved in the subsequent development of endometriosis. In their case-control analysis, Nagle et al. [23] reported that being overweight during late childhood (10 to 16 years old) is associated with a higher risk of endometriosis. Similar study designs have demonstrated an inverse relationship between the risk of endometriosis and $\mathrm{BMI}$, both at diagnosis and during adolescence or early adulthood $[18,24,25]$. These findings provide further evidence that historical body shape and size during early life are closely associated with the subsequent diagnosis of endometriosis. Several possible explanations can be offered: for example, insulin resistance and hyperinsulinemia have been reported in obese adolescent girls, which is associated with increased production of adrenal androgens and decreased plasma levels of sex hormone-binding globulin $[26,27]$. Using the same biological pathway as androgens, insulin-like growth factor (IGF) has been shown to prevent apoptosis of ectopic endometrial cells, and higher plasma and peritoneal fluid IGF-I levels have been reported in women with endometriosis [28,29].

In a study analyzing 5,504 cases of endometriosis that were collected from a large cohort, both BMI at 18 years and current $\mathrm{BMI}$ were significantly inversely associated with endometriosis $(P<0.0001)$ [18]. Obese infertile women with current BMls of $35-39.9 \mathrm{~kg} / \mathrm{m}^{2}$ and $\geq 40 \mathrm{~kg} / \mathrm{m}^{2}$ had a $55 \%$ $(95 \% \mathrm{Cl}, 0.30-0.67)$ and a $62 \%(95 \% \mathrm{Cl}, 0.23-0.62)$ lower risk of endometriosis, compared with the low to normal BMI referent $\left(18.5-22.4 \mathrm{~kg} / \mathrm{m}^{2}\right)$. This negative association between current high $\mathrm{BMI}$ and endometriosis is largely driven by a woman's BMl at 18 years of age, suggesting that there is an etiologically relevant 'early window of exposure', during which higher body size reduces an individual's subsequent risk of developing endometriosis [18]. However, the authors mentioned that it is difficult to confirm that the impact of body size on endometriosis truly precedes the onset of disease, given the inherent impossibility of identifying the precise time point at which endometriosis first appears.

Several possible explanations for the inverse association between $\mathrm{BMI}$ and the diagnosis of endometriosis have been reported. It is well-established that increased body size or obesity is often associated with anovulation and/or oligomenorrhea. Therefore, the chance of menstrual regurgitation in the pelvic cavity can be decreased in women with obesity $[18,30]$. However, epidemiological data have shown that 


\section{Obstetrics \& Gynecology Science}

Juyeon Hong, et al. Endometriosis and adiposity

$\mathrm{BMI}$ is an independent factor associated with the frequency of endometriosis by adjusting for menstrual factors in their analyses. Another explanation is that chronic pain symptoms accompanied by endometriosis induce gastrointestinal symptoms or emotional stress that lead to reduced appetite and food intake, which results in lower body size in women with endometriosis [31,32].

In contrast, some studies assessed various predisposing risk factors relevant to endometriosis, but failed to observe a significant relationship between anthropometry and endometriosis [15,33,34].

\section{Body fat distribution and endometriosis}

In addition to BMI parameters for body size, the effect of body fat distribution on the risk of endometriosis has been investigated. In a study of 45 women with laparoscopically confirmed endometriosis and 46 controls, the waist-to-hip and waist-to-thigh ratios were found to be inversely correlated with the risk of endometriosis in women under 30 years of age, but this correlation disappeared in women aged 30 years or older [35]. They suggested that a specific somatotype with a predominance of peripheral body fat is related to the disease; more peripheral fat has higher estrogen levels in the case group. A recent systematic review analyzed 21 publications and found that lean body habitus, particularly low amounts of adipose tissue and adipose tissue below the waist, are associated with endometriosis [36]. Considering that endometriosis is an estrogen-dependent disease, this finding was consistent with the proposed hypothesis that estrogen influences the distribution and amount of adipose tissue $[37,38]$.

\section{Relationship between body size and disease severity or typology}

A few studies have investigated the relationship between obesity and disease severity in endometriosis but have shown conflicting results. We previously demonstrated that women with advanced stages of endometriosis had lower BMls than those with mild disease in women who had surgically confirmed endometriosis, denoting that BMI was significantly inversely associated with disease severity even after adjusting for age, menstrual history, parity, and marital status [39]. Interestingly, such a relationship was found to be significant in later reproductive-aged women (aged 27-36 years and 37-45 years) but not in the younger group (18-27 years). Although the explanation of this finding is limited, the age-related association between obesity and the severity of endometriosis suggests that the growth of endometrial lesions is influenced by the progressive change in the amount or distribution of body fat that occurs with aging. In contrast, another casecontrol study with 506 women surgically diagnosed with endometriosis showed that lean body mass was associated with a high prevalence of endometriosis, which is consistent with previous studies [31]. However, obesity is associated with a more advanced stage of endometriosis and a reduced frequency of stage I endometriosis.

A case-control study classified different types of endometriosis and found that patients with the lowest BMI $(<18.5)$ had a high risk of deep infiltrating endometriosis (DIE) [40]. Byun et al. [41] assessed the relationships between diverse adiposity measures and the severity and typology of endometriosis; stage IV, ovarian endometrioma, and DIE were associated with the lowest anthropometric and body composition indicators, although they could not determine the causal relationship. They concluded that the association between adiposity and endometriosis severity and typology might be more complicated than a simple correlation.

\section{Biological and in vivo studies on adiposity and risk of endometriosis}

Mediating mechanisms that can explain the inverse relationship between obesity and the risk of endometriosis are poorly understood, but several hypotheses and pathways have been suggested in published research areas.

One potential pathway suggests that adipose tissue macrophages are differently expressed by body size or fat amount. M2 macrophages have anti-inflammatory properties and promote tissue regeneration in injured tissue, while M1 macrophages promote inflammation and inhibit angiogenesis and tissue remodeling $[36,42]$. Research has shown that M2 macrophages may be involved in the development of endometriosis, potentially through the actions of $\mathrm{M} 2$, including angiogenesis and tissue remodeling [43-45]. Interestingly, leanness is associated with a predominance of M2 macro- 


\section{Obstetrics \& Gynecology Science}

Vol. 65, No. 3, 2022

phages, whereas being larger is associated with a predominance of M1 macrophages [36,46].

Adipocytokine (or adipokine), a cytokine family mainly secreted from adipocytes, might be one of the biomolecules that can mediate the adiposity and establishment or progression of endometriosis. Adipokines play various biological roles as immune mediators, regulation of cell survival, inflammation, and angiogenesis, which are also critical functions in the establishment or development of endometriosis [47-51]. In addition, many adipokine levels in circulation are known to correlate with adiposity, such as an increase or decrease in those who are overweight or obese. Considering the anatomical proximity of visceral fat to the pelvic organs where endometriosis commonly occurs, there could be certain paracrine effects of adipokines secreted from visceral fat into the pelvic cavity, which may influence the establishment or progression of endometriosis [52]. Therefore, determining the adipokine levels in the peritoneal cavity with a correlation between an endometriotic condition and visceral fat amount and to study the biological or molecular effects of adipokines on endometriosis would be important to determine the underlying mechanism for biological connections between adiposity and endometriosis. Indeed, some studies have demonstrated aberrant expression of various adipokines in endometriotic peritoneal fluid (PF) and endometriosis lesions [53-57]. We previously reported that resistin concentration is increased in endometriotic PF, and its expression is upregulated in ectopic endometrial tissues compared to that in normal eutopic endometrium [52,53]. Adiponectin is an adipokine with anti-inflammatory and anti-angiogenic properties, and its circulating levels are negatively correlated with obesity $[49,50,58]$. One study found that adiponectin levels in the $\mathrm{PF}$ of women with endometriosis were significantly lower than those of controls, suggesting that this molecule may be an anti-endometriotic factor due to its anti-inflammatory and anti-angiogenic properties [54]. In contrast, our study did not find a significant difference in PF adiponectin levels between the endometriosis and control groups [53]. Despite the findings of aberrant expression of adipokines in various biosamples in patients with endometriosis, the explanation for the causal effect of adiposity on endometriosis is still limited because most studies did not assess the anthropometric indices or did not measure the amount of total or visceral fat or fat distribution in their study subjects. In addition, the correlation between visceral fat mass and the concentrations of adipokines in the peritoneal cavity is not well understood.

An experimental study in mice with induced endometriosis revealed differentially regulated 26 genes in the liver. Among them, six genes were found to be involved in metabolism [59]. Four of the six genes, Cyp2r1, Fabp4, Mrc1, and Rock2, were upregulated and were related to weight loss, whereas two genes, lgfbp1 and Mmd2, were downregulated and linked to obesity. Altered metabolism mediated by the liver contributes to the clinically observed low BMI that is characteristic of women with endometriosis, suggesting the systemic and multiorgan nature of endometriosis [59].

\section{Conclusion}

Obesity and endometriosis are common entities characterized by systemic inflammation [32]. Thus, the finding of an inverse association between these two conditions is interesting but not yet clear. The direction of studies for elucidating this finding can be approached in terms of genetic traits, immune system, and hormonal factors linked to both conditions. Endometriosis is believed to be inherited as a complex genetic trait by which multiple genes confer disease susceptibility and interact with one another and the environment to produce the phenotype $[17,39,60]$. Therefore, genetic factors involved in endometriosis susceptibility might also be associated with those involved in the physiology of adiposity or obesity [17,61].

Although the etiology of endometriosis remains unclear, endometriosis has historically been regarded as a focal disease primarily within the pelvic and peritoneal cavities [62]. However, recent evidence highlights the multiple links between endometriosis and systemic diseases with immunologic and metabolic changes and has identified comorbidities associated with endometriosis, such as autoimmune diseases, cancers, and cardiovascular disease $[63,64]$. The factors that transmit systemic signaling beyond the peritoneal cavity remain unclear; thus, research on extracellular signaling pathways such as exosomes, microRNAs, and stem cell biology in terms of the pathophysiology of endometriosis would provide more information on the systemic nature and complexity of endometriosis [62]. In addition, studies targeting biological substances that specifically function in both adipose tissue metabolism and endometriosis could help better understand the observed relationship between adiposity 


\section{Obstetrics \& Gynecology Science}

Juyeon Hong, et al. Endometriosis and adiposity

and the establishment or behavior of endometriosis.

\section{Conflict of interest}

No potential conflict of interest relevant to this article was reported.

\section{Ethical approval}

The study is not applicable to Institutional Review Board.

\section{Patient consent}

There is no need for patient consent in this review article.

\section{Funding information}

None.

\section{References}

1. Giudice LC, Kao LC. Endometriosis. Lancet 2004;364: 1789-99.

2. Buck Louis GM, Hediger ML, Peterson CM, Croughan $M$, Sundaram R, Stanford J, et al. Incidence of endometriosis by study population and diagnostic method: the ENDO study. Fertil Steril 2011;96:360-5.

3. Bulun SE. Endometriosis. N Engl J Med 2009;360:268-79.

4. Macer ML, Taylor HS. Endometriosis and infertility: a review of the pathogenesis and treatment of endometriosis-associated infertility. Obstet Gynecol Clin North Am 2012;39:535-49.

5. Rogers PA, D'Hooghe TM, Fazleabas A, Gargett CE, Giudice LC, Montgomery GW, et al. Priorities for endometriosis research: recommendations from an international consensus workshop. Reprod Sci 2009;16:335-46.

6. Burney RO, Giudice LC. Pathogenesis and pathophysiology of endometriosis. Fertil Steril 2012;98:511-9.

7. Sampson JA. Metastatic or embolic endometriosis, due to the menstrual dissemination of endometrial tissue into the venous circulation. Am J Pathol 1927;3:93110.43 .

8. Batt RE, Smith RA, Buck Louis GM, Martin DC, Chapron $C$, Koninckx PR, et al. Müllerianosis. Histol Histopathol 2007;22:1161-6.

9. Suginami $H$. A reappraisal of the coelomic metaplasia theory by reviewing endometriosis occurring in unusual sites and instances. Am J Obstet Gynecol 1991;165:214-8.

10. Cramer DW, Wilson E, Stillman RJ, Berger MJ, Belisle $S$, Schiff I, et al. The relation of endometriosis to menstrual characteristics, smoking, and exercise. JAMA 1986;255:1904-8.

11. Missmer SA, Cramer DW. The epidemiology of endometriosis. Obstet Gynecol Clin North Am 2003;30:1-19, vii.

12. Missmer SA, Hankinson SE, Spiegelman D, Barbieri RL, Marshall LM, Hunter DJ. Incidence of laparoscopically confirmed endometriosis by demographic, anthropometric, and lifestyle factors. Am J Epidemiol 2004;160:784-96.

13. McLeod BS, Retzloff MG. Epidemiology of endometriosis: an assessment of risk factors. Clin Obstet Gynecol 2010;53:389-96.

14. Darrow SL, Vena JE, Batt RE, Zielezny MA, Michalek AM, Selman S. Menstrual cycle characteristics and the risk of endometriosis. Epidemiology 1993;4:135-42.

15. Hemmings R, Rivard M, Olive DL, Poliquin-Fleury J, Gagné $D$, Hugo $P$, et al. Evaluation of risk factors associated with endometriosis. Fertil Steril 2004;81:1513-21.

16. Signorello LB, Harlow BL, Cramer DW, Spiegelman D, Hill JA. Epidemiologic determinants of endometriosis: a hospital-based case-control study. Ann Epidemiol 1997;7: 267-741.

17. Ferrero S, Anserini P, Remorgida V, Ragni N. Body mass index in endometriosis. Eur J Obstet Gynecol Reprod Biol 2005; 121:94-8.

18. Shah DK, Correia KF, Vitonis AF, Missmer SA. Body size and endometriosis: results from 20 years of follow-up within the Nurses' Health Study II prospective cohort. Hum Reprod 2013;28:1783-92.

19. Parazzini F, Chiaffarino F, Surace M, Chatenoud L, Cipriani S, Chiantera V, et al. Selected food intake and risk of endometriosis. Hum Reprod 2004;19:1755-9.

20. Moini A, Malekzadeh F, Amirchaghmaghi E, Kashfi F, Akhoond MR, Saei M, et al. Risk factors associated with endometriosis among infertile Iranian women. Arch Med Sci 2013;9:506-14. 


\section{Obstetrics \& Gynecology Science}

Vol. 65, No. 3, 2022

21. Shahbazi S, Shahrabi-Farahani M. Evaluation of the correlation between body mass index and endometriosis among Iranian fertile women. Gynecol Endocrinol 2016;32:157-60.

22. Liu Y, Zhang W. Association between body mass index and endometriosis risk: a meta-analysis. Oncotarget 2017; 8:46928-36.

23. Nagle CM, Bell TA, Purdie DM, Treloar SA, Olsen CM, Grover $S$, et al. Relative weight at ages 10 and 16 years and risk of endometriosis: a case-control analysis. Hum Reprod 2009;24:1501-6.

24. Hediger ML, Hartnett HJ, Louis GM. Association of endometriosis with body size and figure. Fertil Steril 2005;84: 1366-74.

25. Vitonis AF, Baer HJ, Hankinson SE, Laufer MR, Missmer SA. A prospective study of body size during childhood and early adulthood and the incidence of endometriosis. Hum Reprod 2010;25:1325-34.

26. Caprio S, Bronson M, Sherwin RS, Rife F, Tamborlane WV. Co-existence of severe insulin resistance and hyperinsulinaemia in pre-adolescent obese children. Diabetologia 1996;39:1489-97.

27. Baer HJ, Colditz GA, Willett WC, Dorgan JF. Adiposity and sex hormones in girls. Cancer Epidemiol Biomarkers Prev 2007;16:1880-8.

28. Koutsilieris $M$, Mastrogamvrakis $G$, Lembessis $P$, Sourla $A$, Miligos $S$, Michalas $S$. Increased insulin-like growth factor 1 activity can rescue KLE endometrial-like cells from apoptosis. Mol Med 2001;7:20-6.

29. Kim JG, Suh CS, Kim SH, Choi YM, Moon SY, Lee JY. Insulin-like growth factors (IGFs), IGF-binding proteins (IGFBPS), and IGFBP-3 protease activity in the peritoneal fluid of patients with and without endometriosis. Fertil Steril 2000;73:996-1000.

30. Selak V, Farquhar C, Prentice A, Singla A. Danazol for pelvic pain associated with endometriosis. Cochrane Database Syst Rev 2001;(4):CD000068.

31. Holdsworth-Carson SJ, Dior UP, Colgrave EM, Healey M, Montgomery GW, Rogers PAW, et al. The association of body mass index with endometriosis and disease severity in women with pain. J Endometriosis Pelvic Pain Disorders 2018;10:79-87.

32. Pantelis A, Machairiotis N, Lapatsanis DP. The formidable yet unresolved interplay between endometriosis and obesity. ScientificWorldJournal 2021;2021:6653677.
33. Ashrafi M, Sadatmahalleh SJ, Akhoond MR, Talebi M. Evaluation of risk factors associated with endometriosis in infertile women. Int J Fertil Steril 2016;10:11-21.

34. Tang Y, Zhao M, Lin L, Gao Y, Chen GQ, Chen S, et al. Is body mass index associated with the incidence of endometriosis and the severity of dysmenorrhoea: a casecontrol study in China? BMJ Open 2020;10:e037095.

35. McCann SE, Freudenheim JL, Darrow SL, Batt RE, Zielezny MA. Endometriosis and body fat distribution. Obstet Gynecol 1993;82(4 Pt 1):545-9.

36. Backonja U, Buck Louis GM, Lauver DR. Overall adiposity, adipose tissue distribution, and endometriosis: a systematic review. Nurs Res 2016;65:151-66.

37. Ley CJ, Lees B, Stevenson JC. Sex- and menopauseassociated changes in body-fat distribution. Am J Clin Nutr 1992;55:950-4.

38. Jasieńska G, Ziomkiewicz A, Ellison PT, Lipson SF, Thune I. Large breasts and narrow waists indicate high reproductive potential in women. Proc Biol Sci 2004;271:1213-7.

39. Yi KW, Shin JH, Park MS, Kim T, Kim SH, Hur JY. Association of body mass index with severity of endometriosis in Korean women. Int J Gynaecol Obstet 2009;105:39-42.

40. Lafay Pillet MC, Schneider A, Borghese B, Santulli P, Souza $C$, Streuli I, et al. Deep infiltrating endometriosis is associated with markedly lower body mass index: a 476 case-control study. Hum Reprod 2012;27:265-72.

41. Byun J, Peterson CM, Backonja U, Taylor RN, Stanford $J B$, Allen-Brady KL, et al. Adiposity and endometriosis severity and typology. J Minim Invasive Gynecol 2020;27: 1516-23.

42. Murray PJ, Wynn TA. Protective and pathogenic functions of macrophage subsets. Nat Rev Immunol 2011;11: 723-37.

43. Smith KA, Pearson CB, Hachey AM, Xia DL, Wachtman LM. Alternative activation of macrophages in rhesus macaques (Macaca mulatta) with endometriosis. Comp Med 2012;62:303-10.

44. Wang Y, Fu Y, Xue S, Ai A, Chen H, Lyu Q, et al. The M2 polarization of macrophage induced by fractalkine in the endometriotic milieu enhances invasiveness of endometrial stromal cells. Int J Clin Exp Pathol 2013;7:194-203.

45. Wang $Y$, Chen $H$, Wang $N$, Guo H, Fu Y, Xue S, et al. Combined $17 \beta$-estradiol with TCDD promotes M2 polarization of macrophages in the endometriotic milieu with aid of the interaction between endometrial stromal cells 


\section{Obstetrics \& Gynecology Science}

Juyeon Hong, et al. Endometriosis and adiposity

and macrophages. PLoS One 2015;10:e0125559.

46. Lumeng CN, Bodzin JL, Saltiel AR. Obesity induces a phenotypic switch in adipose tissue macrophage polarization. J Clin Invest 2007;117:175-84.

47. Tilg H, Moschen AR. Adipocytokines: mediators linking adipose tissue, inflammation and immunity. Nat Rev Immunol 2006;6:772-83.

48. Silswal N, Singh AK, Aruna B, Mukhopadhyay S, Ghosh S, Ehtesham NZ. Human resistin stimulates the pro-inflammatory cytokines TNF-alpha and IL-12 in macrophages by NF-kappaB-dependent pathway. Biochem Biophys Res Commun 2005;334:1092-101.

49. Yokota T, Oritani K, Takahashi I, Ishikawa J, Matsuyama A, Ouchi N, et al. Adiponectin, a new member of the family of soluble defense collagens, negatively regulates the growth of myelomonocytic progenitors and the functions of macrophages. Blood 2000;96:1723-32.

50. Bråkenhielm E, Veitonmäki N, Cao R, Kihara S, Matsuzawa $Y$, Zhivotovsky $B$, et al. Adiponectin-induced antiangiogenesis and antitumor activity involve caspasemediated endothelial cell apoptosis. Proc Natl Acad Sci U S A 2004;101:2476-81.

51. Kalaitzopoulos DR, Lempesis IG, Samartzis N, Kolovos G, Dedes I, Daniilidis A, et al. Leptin concentrations in endometriosis: a systematic review and meta-analysis. J Reprod Immunol 2021;146:103338.

52. Oh YK, Ha YR, Yi KW, Park HT, Shin JH, Kim T, et al. Increased expression of resistin in ectopic endometrial tissue of women with endometriosis. Am J Reprod Immunol 2017;78:e12726.

53. Yi KW, Shin JH, Park HT, Kim T, Kim SH, Hur JY. Resistin concentration is increased in the peritoneal fluid of women with endometriosis. Am J Reprod Immunol 2010;64: 318-23.

54. Takemura Y, Osuga Y, Harada M, Hirata T, Koga K, Yoshino $\mathrm{O}$, et al. Concentration of adiponectin in peritone- al fluid is decreased in women with endometriosis. Am J Reprod Immunol 2005;54:217-21.

55. Zendron C, Gonçalves HF, Cavalcante FS, Pereira TR, Evangelista $A$, Ramos CF, et al. Increased expression of the leptin receptor in human ovaries affected by endometrioma and detection of high levels of leptin in the ovarian endometriomal fluid. J Ovarian Res 2014;7:2.

56. Choi YS, Oh HK, Choi JH. Expression of adiponectin, leptin, and their receptors in ovarian endometrioma. Fertil Steril 2013;100:135-41.e1-2.

57. Alviggi C, Clarizia R, Castaldo G, Matarese G, Colucci $C C$, Conforti $S$, et al. Leptin concentrations in the peritoneal fluid of women with ovarian endometriosis are different according to the presence of a 'deep' or 'superficial' ovarian disease. Gynecol Endocrinol 2009;25:610-5.

58. Hu E, Liang P, Spiegelman BM. AdipoQ is a novel adipose-specific gene dysregulated in obesity. J Biol Chem 1996;271:10697-703.

59. Goetz TG, Mamillapalli R, Taylor HS. Low body mass index in endometriosis is promoted by hepatic metabolic gene dysregulation in mice. Biol Reprod 2016;95:115.

60. Zondervan KT, Cardon LR, Kennedy SH. The genetic basis of endometriosis. Curr Opin Obstet Gynecol 2001;13: 309-14.

61. Blundell JE, Cooling J. High-fat and low-fat (behavioural) phenotypes: biology or environment? Proc Nutr Soc 1999; 58:773-7.

62. Alderman MH 3rd, Yoder N, Taylor HS. The systemic effects of endometriosis. Semin Reprod Med 2017;35:263-70.

63. Kvaskoff M, Mu F, Terry KL, Harris HR, Poole EM, Farland L, et al. Endometriosis: a high-risk population for major chronic diseases? Hum Reprod Update 2015;21:500-16.

64. Gemmill JA, Stratton P, Cleary SD, Ballweg ML, Sinaii N. Cancers, infections, and endocrine diseases in women with endometriosis. Fertil Steril 2010;94:1627-31. 